\title{
Microscopic Findings Death Relationship
}

National Cancer Institute

\section{Source}

National Cancer Institute. Microscopic Findings Death Relationship. NCI Thesaurus. Code C119879.

An indication or description of a correlation between death and a microscopic finding. 